\title{
Residents' Perceptions of Faculty Behaviors and Resident Burnout: a Cross-Sectional Survey Study Across a Large Health Care Organization
}

\author{
Liselotte N. Dyrbye, MD, MHPE ${ }^{1}$, Andrea N. Leep Hunderfund, MD, MHPE ${ }^{1,2}$, \\ Susan Moeschler, $M D^{7}$, Brianna Vaa, $M D^{7}$, Eric Dozois, $M D^{7}$, Richard C Winters, $M D^{7}$, \\ Daniel Satele, $B A^{3}$, and Colin P. West, $M D, P h D^{7}$ \\ 'Mayo Clinic, Rochester, MN, USA; ${ }^{2}$ Mayo Clinic Alix School of Medicine, Rochester, MN, USA; ${ }^{3}$ Department of Health Sciences Research, Mayo \\ Clinic, Rochester, MN, USA.
}

\begin{abstract}
BACKGROUND: Data suggests the learning environment factors influence resident well-being. The authors conducted an assessment of how residents' perceptions of faculty-resident relationships, faculty professional behaviors, and afforded autonomy related to resident burnout. METHODS: All residents at one organization were surveyed in 2019 using two items from the Maslach Burnout Inventory and the faculty relationship subscale of the Johns Hopkins Learning Environment Scale (JHLES, range 6 to 30). Residents were also asked about faculty professional behaviors (range 0 to 30), and satisfaction with autonomy across various clinical settings.
\end{abstract}

RESULTS: A total of 762/1146 (66.5\%) residents responded to the survey. After adjusting for age, gender, postgraduate year, and specialty, lower (less favorable) JHLES-faculty relationship subscale score (parameter estimate, $-3.08,95 \%$ CI $-3.75,-2.41, p<0.0001$ ), fewer observed faculty professional behaviors (parameter estimate, $-3.34,95 \%$ CI $-4.02,-2.67, p<0.0001)$, and lower odds of satisfaction with autonomy in the intensive care settings (OR 0.46, 95\% CI 0.30, 0.70, $p=0.001$ ), but not other care settings, were reported by residents with burnout in comparison to those without. Similar relationships were observed when emotional exhaustion and depersonalization were analyzed separately as continuous variables.

CONCLUSION: In this cohort, resident perceptions of faculty relationships, faculty professional behaviors, and satisfaction with autonomy in the intensive care unit were associated with resident burnout. Additional longitudinal studies are needed to elucidate the direction of these relationships and determine if faculty development can reduce resident burnout.

J Gen Intern Med 36(7):1906-13

DOI: $10.1007 / \mathrm{s} 11606-020-06452-3$

(c) Society of General Internal Medicine 2021

Received June 15, 2020

Accepted December 13, 2020

Published online January 22, 2021
T here is a high prevalence of burnout among residents. $^{1-4}$ This is grounds for concern, as resident well-being impacts quality of patient care and residents' competency, career satisfaction, specialty choice, and personal health. ${ }^{1,2,4-8}$ A complex array of factors within the clinical learning environment influence resident wellbeing. 4,9,10 Conceptually, burnout results when job demands (e.g., excessive workload, administrative burdens, inadequate technology usability) exceed job resources (e.g., professional relationships, autonomy, meaning and purpose in work, professional development, organizational culture). ${ }^{11}$ Specifically within the learning environment, high faculty demands, inadequate emotional support from faculty, stressful faculty relationships, hostile faculty behaviors, poor mentorship relationships, and insufficient autonomy are associated with higher risk of burnout among residents..$^{3,4,12,13}$ On the other hand, residents who report greater opportunities for learning, better teaching quality, and more frequent direct observation and feedback - all of which increase "job resources" - are less likely to have burnout."13-15 Although previous studies are informative, most included small numbers of learners, involved one specialty, were conducted outside the USA, or did not control for potential confounders.

The Accreditation Council for Graduate Medical Education (ACGME) common program requirements state that clinical settings where graduate medical education occurs must ensure learning environments promote resident well-being and that the health of learning environments must be monitored. ${ }^{16}$ Additionally, the ACGME common program requirements specify that faculty have a direct role in creating and sustaining an effective learning environment, and faculty development must occur to equip the faculty with the capacity to do so. ${ }^{16}$ To guide such efforts, we surveyed residents in all specialty training programs across a large health system to identify faculty behaviors associated with resident burnout. We hypothesized that poor faculty-resident relationships, suboptimal faculty professional behaviors, and dissatisfaction with autonomy would be associated with resident burnout. 


\section{METHODS}

As previously described, ${ }^{17}$ we surveyed all 1146 residents at Mayo Clinic (training sites in Rochester, Minnesota; Scottsdale and Phoenix, Arizona; and Jacksonville, Florida and community-based hospitals and health care facilities in the Midwest) in early 2019. The residents received an e-mail with a link to the web survey. Residents who did not respond to the electronic survey were mailed a paper survey. Participation was optional and anonymous. The study was approved by the Mayo Clinic Institutional Review Board.

\section{Faculty-Resident Relationships}

We measured resident perceptions of their relationships with faculty using the faculty relationship subscale of the Johns Hopkins Learning Environment Scale (JHLES). ${ }^{18,19}$ Although developed to measure the learning environment within medical schools, the underlying construct and domains represented apply broadly to medical learners in general. The word "Mayo Clinic" was used to replace the term "SOM" (school of medicine) in the original JHLES. These six items explore specific faculty behaviors and attitudes related to provision of support, genuine interest in the resident, concern about resident well-being, role-modeling behaviors, accessibility, and trustworthiness. Responses to the JHLES-faculty relationship subscale were summed, with a higher score indicating more positive faculty-resident relationships (range 6 to 30). ${ }^{18,19}$ In this cohort of residents, the Cronbach alpha for the JHLES-faculty relationship subscale was 0.93 . Description of the development of the JHLES and supporting validity evidence in samples of medical students has been published. ${ }^{18,19}$

\section{Faculty Professional Behaviors}

Using an iterative process involving all authors, we selected and developed items to measure faculty professional behaviors hypothesized to influence resident well-being. Items exploring faculty respect, time management, and feedback originated from the Association of American Medical Colleges questionnaires administered to medical students assessing the educational environment. ${ }^{20,21}$ We supplemented these questions with items measuring faculty role-modeling of well-being/ self-care, role-modeling self-directed learning, and encouraging diversity of viewpoints. Collectively, these items covered aspects of professional behaviors expected by the ACGME of faculty. ${ }^{16}$ Residents were asked how often the six professional behaviors/attitudes were demonstrated by the teaching faculty (never, almost never, sometimes, fairly often, very often, and always). We summed residents' responses to the items (including only those who had responded to all the faculty behavior items) with a higher score representing greater exposure to faculty professional behaviors (range 0 to 30 ).

\section{Satisfaction with Autonomy}

In addition, we developed four items to explore resident satisfaction with the degree of autonomy typically afforded during clinical decision-making for patients in the following clinical contexts: intensive care, undergoing a procedure or surgery, admitted to a non-intensive care hospital bed, and outpatient, non-procedural setting. Medical and surgical intensive care units are closed and run by intensivists who are onsite 24/7. Fellows are often part of the surgical and inpatient care team apart from general medical services. Residents were asked to rate their level of satisfaction across a 5-point Likert scale or indicate the setting was not applicable to them. Responses were dichotomized to satisfied ("very satisfied" and "satisfied") and not satisfied ("neither satisfied nor dissatisfied," "dissatisfied," and "very dissatisfied"). All of these items were reviewed, edited, and approved by the authors and can be found in the Appendix.

\section{Burnout}

We measured symptoms of burnout using two items from the Maslach Burnout Inventory (MBI; licensed for use by mindgarden.com). These two items were chosen due to the length and cost of using the full MBI and because previous validity work in over 10,000 physicians and medical students supports that endorsing symptoms weekly or more often to either of these two items (i.e., having a high score) strongly relates to patient care and physician outcomes with magnitudes of association comparable to when the full 22-item MBI is used. ${ }^{22,23}$ When compared to the corresponding emotional exhaustion and depersonalization subscales of the full MBI, each of these two items had areas under the receiver operating characteristic curve of over 0.90 and strongly positive likelihood ratios (14.9 and 23.4 respectively). For these items, the response options ranged from "never" to "every day" on a 7-point scale with those who endorse a frequency of once or more per week considered to have high emotional exhaustion or high depersonalization; individuals with a high score on either item were considered to have symptoms of burnout. ${ }^{22,23}$

\section{Demographics}

Available demographic information included age, gender, postgraduate year, and specialty. Residents were categorized into 1 of 8 specialty areas: primary care (general internal medicine, family medicine, and general pediatrics and adolescent medicine), general surgery, surgical specialty (neurologic surgery, obstetrics and gynecology, ophthalmology, orthopedics, otolaryngology, peripheral nerve surgery, plastics, thoracic, vascular, oral and maxillofacial, orthodontics, surgical critical care, urology), radiology (diagnostic radiology, interventional radiology-integrated), anesthesiology, pathology/ laboratory medicine, other medical specialties (dermatology, neurology [child and adolescent neurology, multiple sclerosis, and neurology], physical medicine/rehabilitation, psychiatry, 
emergency medicine, and radiation oncology), or other (transitional year).

\section{Statistical Analysis}

The primary analysis involved descriptive summary statistics. We used Kruskal-Wallis, Fisher exact, and chi-squared tests to explore associations between variables. Simple logistic and linear regression was used to evaluate relationships. We conducted multivariable logistic and linear regression analysis to evaluate associations between variables and (a) JHLESfaculty relationship subscale score, (b) observed faculty professional behaviors collectively (summed number of professional behaviors observed) and individually, and (c) satisfaction with autonomy at the individual item level. Multivariable models included age, gender, postgraduate year, and specialty in addition to one of the three burnout-related variables at a time: (a) burnout as a dichotomous variable; (b) emotional exhaustion as a continuous variable; or (c) depersonalization as a continuous variable. We used a 5\% type I error rate and two-sided alternative hypotheses using SAS version 9 (SAS Institute, Inc.) for all analyses.

\section{RESULTS}

Demographics, professional characteristics (postgraduate year, specialty, training site), and prevalence of burnout of the $762 / 1146$ (66.5\%) residents who responded to the survey and how responders compared to non-responders have been previously published. ${ }^{17}$

The mean (SD) JHLES-faculty relationship subscale score was 24.9 (4.56). Distribution of responses to each of the six JHLES questions is shown in Table 1. The vast majority of residents "strongly agreed" or "agreed" with each of the items. However, 9.6\% (72/750) "disagreed" or "strongly disagreed" that there were faculty in whom they felt comfortable confiding and $8.5 \%$ (64/751) "disagreed" or "strongly disagreed" that faculty take the time to get to know them.

The mean (SD) faculty professional behavior score was 23.0 (4.7). Over three-quarters of residents reported that faculty were "very often" or "always" respectful of house staff and other physicians $(650 / 755,86.1 \%)$, managed their time and schedule well $(583 / 754,77.3 \%)$, and demonstrated selfdirected learning (590/754, 78.2\%). Approximately two-thirds $(508 / 755,67.3 \%)$ indicated faculty "very often" or "always" encouraged diversity of viewpoints. Just over half reported that faculty "very often" or "always" provided direction and constructive feedback $(430 / 755,56.9 \%)$ and role-modeled well-being/self-care behaviors (436/754, 57.8\%).

Most were "satisfied" or "very satisfied" with the level of autonomy provided in any of the four clinical settings. Satisfaction with provided autonomy was greatest in non-intensive care unit hospital $(567 / 626,90.5 \%)$ and outpatient settings $(580 / 649,89.4 \%)$.

\section{Association Between Faculty-Resident Rela- tionships and Resident Burnout}

Less favorable JHLES-faculty subscale scores were reported by residents who had burnout (mean [SD], 22.7 [4.9] vs 25.9 [4.0], $p<0.001)$ in comparison to residents without burnout. This relationship persisted after adjusting for age, gender, postgraduate year, and specialty with lower ratings of relationships with faculty independently associated with burnout (JHLES-faculty relationship subscale score parameter estimate, $-3.08,95 \% \mathrm{CI}-3.75,-2.40, p<0.0001)$. The strength of the relationship is substantial and likely educationally important given the clinically meaningful effect size (as the SD for the JHLES was 4.56, the parameter estimate reflects a 0.67 SD effect size). ${ }^{24}$

Figure 1 a shows that lower scores on the JHLES-faculty relationship subscale were associated with greater severity of both emotional exhaustion and depersonalization (both $p<$ 0.001 ). These relationships remained statistically significant after adjusting for age, sex, postgraduate year, and specialty. In these multivariable models, each 1-point higher emotional exhaustion score was independently associated with less favorable faculty-resident relationships (parameter estimate, $1.08,95 \%$ CI $-1.28,-0.89, p<0.0001)$. Similarly, each 1 point higher depersonalization score was independently associated with less favorable faculty-resident relationships (parameter estimate, $-0.98,95 \% \mathrm{CI}-1.16,-0.80, p<0.0001)$.

\section{Association Between Faculty Professional Behaviors and Resident Burnout}

Fewer faculty professional behaviors were reported by residents with burnout (mean scale score 20.5 [4.32] vs. 24.2 [4.12], $p<0.0001$ ) versus those without burnout. On multivariable analysis adjusting for age, gender, postgraduate year, and specialty, fewer observed faculty professional behaviors remained independently associated with resident burnout (parameter estimate, - 3.34, 95\% CI $-4.02,-2.67, p<0.0001)$. The observed effect size is clinically meaningful. ${ }^{24}$

As the frequency of observed faculty professional behaviors decreased, the severity of both emotional exhaustion and depersonalization increased (both $p<0.001$; Fig. 1b). After adjusting for age, sex, postgraduate year, and specialty, each 1-point higher emotional exhaustion score was independently associated with lower total observed faculty professional behavior score (parameter estimate, $-1.11,95 \% \mathrm{CI}-1.31$, $0.92, p<0.0001)$. Similarly, each 1-point higher depersonalization score was independently associated with lower total observed faculty professional behavior score (parameter estimate, $-1.20,95 \%$ CI $-1.37,-1.02, p<0.0001)$.

Additionally, each faculty professional behavior was reported less often by residents with burnout in comparison to residents without burnout (Table 2). After adjusting for age, gender, postgraduate year, and specialty, each 1-point lower score (indicating lower frequency) for exposure to each faculty 
Table 1 Resident-Reported Faculty-Resident Relationships, Faculty Professional Behaviors, and Satisfaction with Autonomy

\begin{tabular}{|c|c|c|c|c|c|c|}
\hline Faculty-resident relationships & $\begin{array}{l}\text { Strongly } \\
\text { agree, } N(\%)\end{array}$ & $\begin{array}{l}\text { Agree, } N \\
(\%)\end{array}$ & Neither, $N(\%)$ & $\begin{array}{l}\text { Disagree, } N \\
(\%)\end{array}$ & \multicolumn{2}{|c|}{ Strongly disagree, $N(\%)$} \\
\hline $\begin{array}{l}\text { I feel that the faculty I encounter are } \\
\text { supportive of my professional goals }\end{array}$ & $340(45.3 \%)$ & $\begin{array}{l}338 \\
(45.0 \%)\end{array}$ & $57(7.6 \%)$ & $10(1.3 \%)$ & \multicolumn{2}{|l|}{$6(0.8 \%)$} \\
\hline $\begin{array}{l}\text { I feel that faculty members have taken the } \\
\text { time to get to know me }\end{array}$ & $230(30.6 \%)$ & $\begin{array}{l}334 \\
(44.5 \%)\end{array}$ & $123(16.4 \%)$ & $52(6.9 \%)$ & \multicolumn{2}{|l|}{$12(1.6 \%)$} \\
\hline $\begin{array}{l}\text { I feel that the faculty I encounter genuinely } \\
\text { care about my well-being }\end{array}$ & $271(36.1 \%)$ & $\begin{array}{l}319 \\
(42.5 \%)\end{array}$ & $118(15.7 \%)$ & $30(4.0 \%)$ & \multicolumn{2}{|l|}{$12(1.6 \%)$} \\
\hline $\begin{array}{l}\text { I've encountered an abundance of positive, } \\
\text { inspiring faculty role models }\end{array}$ & $326(43.4 \%)$ & $\begin{array}{l}295 \\
(39.3 \%)\end{array}$ & $95(12.6 \%)$ & $25(3.3 \%)$ & \multicolumn{2}{|l|}{$10(1.3 \%)$} \\
\hline $\begin{array}{l}\text { There are faculty members that I feel } \\
\text { comfortable confiding in when important } \\
\text { concerns come up }\end{array}$ & $291(38.8 \%)$ & $\begin{array}{l}291 \\
(38.8 \%)\end{array}$ & $96(12.8 \%)$ & $52(6.9 \%)$ & \multicolumn{2}{|l|}{$20(2.7 \%)$} \\
\hline $\begin{array}{l}\text { There are faculty advisors that are readily } \\
\text { accessible and interested in residents }\end{array}$ & $352(47.0 \%)$ & $\begin{array}{l}312 \\
(41.7 \%)\end{array}$ & $57(7.6 \%)$ & $19(2.5 \%)$ & \multicolumn{2}{|l|}{$9(1.2 \%)$} \\
\hline Faculty professional behaviors & Always & $\begin{array}{l}\text { Very } \\
\text { often }\end{array}$ & Fairly often & Sometimes & \multirow{2}{*}{$\begin{array}{l}\text { never } \\
2(0.3 \%)\end{array}$} & Never \\
\hline $\begin{array}{l}\text { Being respectful of house staff and other } \\
\text { physicians }\end{array}$ & $277(36.7 \%)$ & $\begin{array}{l}373 \\
(49.4 \%)\end{array}$ & $84(11.1 \%)$ & $19(2.5 \%)$ & & $0(0.0 \%)$ \\
\hline $\begin{array}{l}\text { Being on time and managing a schedule } \\
\text { well }\end{array}$ & $176(23.3 \%)$ & $\begin{array}{l}407 \\
(54.0 \%)\end{array}$ & $135(17.9 \%)$ & $30(4.0 \%)$ & $6(0.8 \%)$ & $0(0.0 \%)$ \\
\hline $\begin{array}{l}\text { Providing direction and constructive } \\
\text { feedback }\end{array}$ & $140(18.5 \%)$ & $\begin{array}{l}290 \\
(38.4 \%)\end{array}$ & $201(26.6 \%)$ & $107(14.2 \%)$ & $16(2.1 \%)$ & $1(0.1 \%)$ \\
\hline $\begin{array}{l}\text { Role-modeling wellness/self-care behav- } \\
\text { iors }\end{array}$ & $149(19.8 \%)$ & $\begin{array}{l}287 \\
(38.1 \%)\end{array}$ & $183(24.3 \%)$ & $107(14.2 \%)$ & $24(3.2 \%)$ & $4(0.5 \%)$ \\
\hline $\begin{array}{l}\text { Finding resources in the moment needed } \\
\text { to provide patient care }\end{array}$ & $249(33.0 \%)$ & 341 & $116(15.4 \%)$ & $44(5.8 \%)$ & $3(0.4 \%)$ & $1(0.1 \%)$ \\
\hline $\begin{array}{l}\text { Encouraging free and open discussion of } \\
\text { viewpoints, ideas, and beliefs }\end{array}$ & $193(25.6 \%)$ & $\begin{array}{l}315 \\
(41.7 \%)\end{array}$ & $135(17.9 \%)$ & $80(10.6 \%)$ & $30(4.0 \%)$ & $2(0.3 \%)$ \\
\hline Satisfaction with autonomy & Very satisfied & Satisfied & $\begin{array}{l}\text { Neither satisfied } \\
\text { nor dissatisfied }\end{array}$ & Dissatisfied & \multirow{2}{*}{$\begin{array}{l}\text { Very } \\
\text { dissatisfied } \\
9(1.6 \%)\end{array}$} & \multirow{2}{*}{$\begin{array}{l}\text { Not } \\
\text { applicable } \\
198\end{array}$} \\
\hline Patients in an intensive care unit & $208(37.6 \%)$ & $\begin{array}{l}217 \\
(39.2 \%)\end{array}$ & $86(15.6 \%)$ & $33(6.0 \%)$ & & \\
\hline Patients undergoing a procedure or surgery & $266(41.8 \%)$ & $\begin{array}{l}261 \\
(41.0 \%)\end{array}$ & $71(11.2 \%)$ & $32(5.0 \%)$ & $6(0.9 \%)$ & 116 \\
\hline $\begin{array}{l}\text { Patients admitted to a non-intensive care } \\
\text { unit hospital bed }\end{array}$ & $369(58.9 \%)$ & $\begin{array}{l}198 \\
(31.6 \%)\end{array}$ & $43(6.9 \%)$ & $13(2.1 \%)$ & $3(0.5 \%)$ & 124 \\
\hline $\begin{array}{l}\text { Patients seen in the outpatient setting (non- } \\
\text { procedural) }\end{array}$ & $357(55.0 \%)$ & $\begin{array}{l}223 \\
(34.4 \%)\end{array}$ & $56(8.6 \%)$ & $6(0.9 \%)$ & $7(1.1 \%)$ & 102 \\
\hline
\end{tabular}

*Faculty relationship subscale of the Johns Hopkins Learning Environment Scale

professional behavior item was associated with a $1.79-2.07$ higher odds of burnout (Table 3).

\section{Association Between Satisfaction with Autonomy and Resident Burnout}

Residents with burnout were less likely to report being satisfied with the level of autonomy afforded to them to provide care for patients in an intensive care unit (OR 0.51, 95\% CI $0.27-0.97, p=0.04)$, patients undergoing a procedure or surgery (OR $0.41,95 \%$ CI $0.21-0.80, p=0.01)$, and patients admitted to a non-intensive care unit hospital bed (OR 0.37 , 95\% CI $0.14-1.00, p=0.05$; Table 4 ) relative to the residents without burnout. After adjusting for age, gender, postgraduate year, and specialty, residents with burnout had lower odds of being satisfied with autonomy provided for patients in an intensive care unit (OR 0.46, 95\% CI 0.30, 0.70, $p<0.001$ ).

Statistically significant relationships were found between satisfaction with autonomy providing care for patients in the intensive care unit and non-intensive care unit hospital setting and severity of emotional exhaustion and depersonalization. After adjusting for age, gender, postgraduate year, and specialty, satisfaction with autonomy provided for patients in an intensive care unit was associated with lower emotional exhaustion (for each 1-point higher score for satisfaction with autonomy, OR $0.8295 \%$ CI $0.71,0.93, p=0.003$ ) and depersonalization (for each 1-point higher score for satisfaction with autonomy, OR $0.79,95 \%$ CI $0.70,0.89, p=0.001$ ) scores. Similarly, satisfaction with autonomy provided for patients in a non-intensive care unit hospital setting was associated with a lower emotional exhaustion (for each 1-point higher score for satisfaction with autonomy, OR $0.82,95 \%$ CI $0.69,0.98, p=0.03$ ) and depersonalization (for each 1-point higher score for satisfaction with autonomy, OR $0.78,95 \%$ CI $0.67,0.91, p=0.002$ ) scores, after adjusting for age, gender, postgraduate year, and specialty.

\section{DISCUSSION}

In this large cohort of residents in all specialty training programs across a large health system, resident perceptions of their relationships with faculty, observed faculty professional behaviors, and satisfaction with the degree of autonomy afforded to them during patient care were associated with resident burnout. These findings persisted after adjusting for age, gender, postgraduate year, and specialty. Similar findings 
a

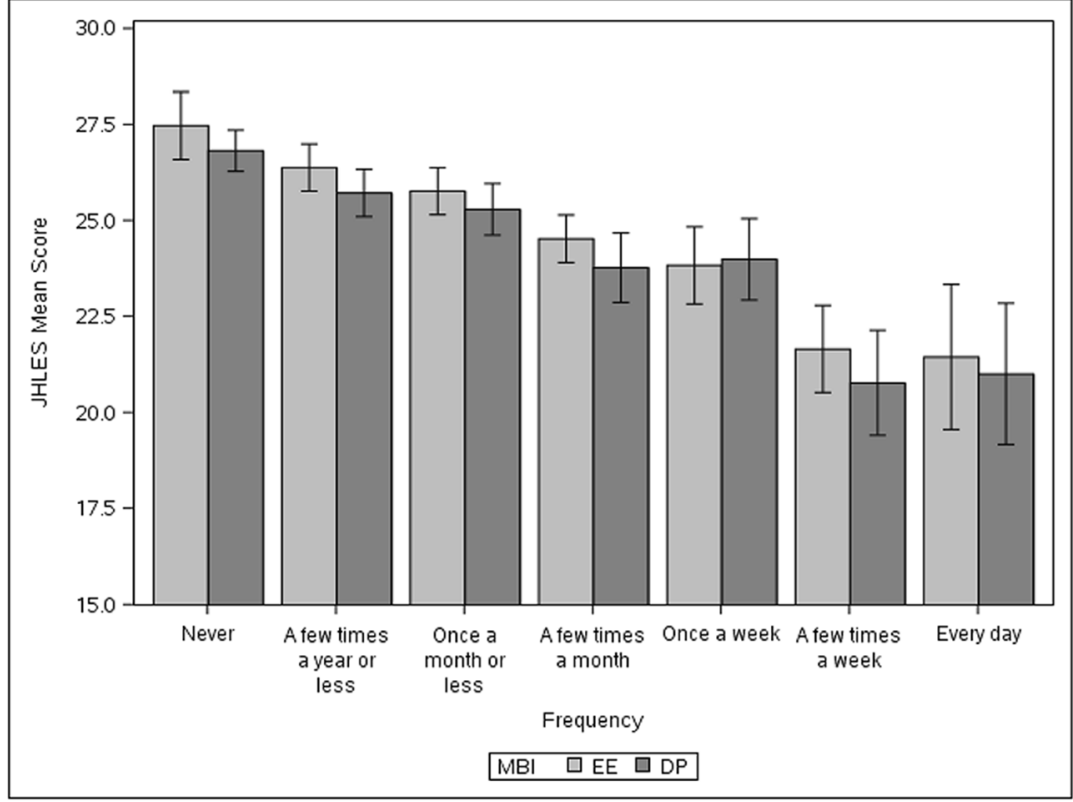

b

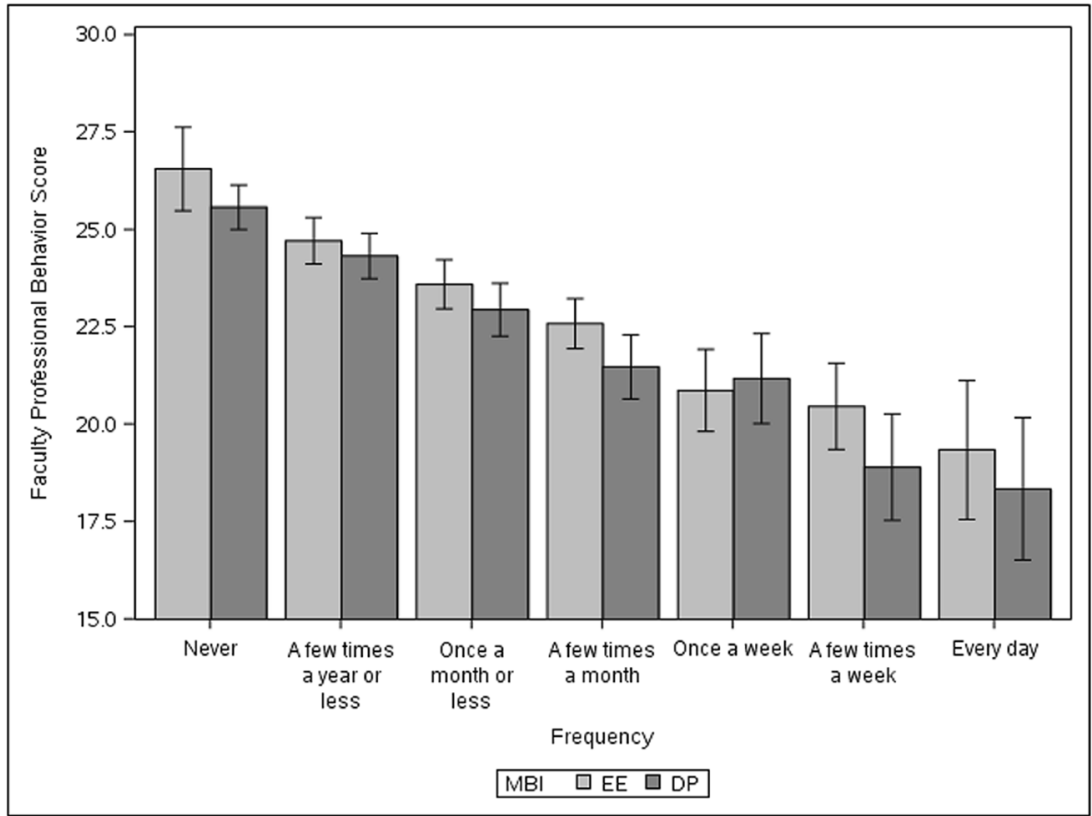

Fig. 1 Severity of emotional exhaustion (EE) and depersonalization (DP) increased as reported quality of faculty relationships decreased as measured by the faculty relationship subscale of the Johns Hopkins Learning Environment Scale (JHLES) (both $p<0.001$, (a); error bars represent $95 \%$ CI for each category). Severity of emotional exhaustion and depersonalization increased and observe faculty professional behaviors decreased (both $p<0.001$, (b)).

were observed when severity of emotional exhaustion or depersonalization was examined separately.

These findings add to the literature demonstrating that faculty behaviors relate to resident well-being. ${ }^{1,15,25,26} \mathrm{Al}-$ though additional work is needed to clarify the temporal relationships between faculty behaviors and burnout, these findings suggest educational leaders should select and develop faculty who support, inspire, and connect well with trainees. Our study identifies specific areas where faculty development may be most useful, including time management (e.g., strategies for teaching in the busy clinical/hospital setting), learning climate, feedback, role-modeling life-long learning and selfcare, and facilitating open dialog. Institutional policies and other barriers that interfere with teaching, positive faculty behaviors, and being accessible to learners should be also addressed as part of a comprehensive organizational strategy to promote a culture of well-being. ${ }^{4}$

Among residents in this cohort, satisfaction with autonomy in clinical decision-making for patients in the intensive care 
Table 2 Frequency of Resident-Observed Faculty Professional Behaviors and Burnout

\begin{tabular}{|c|c|c|c|c|}
\hline & $\begin{array}{l}\text { Burnout } \\
(N=236)\end{array}$ & $\begin{array}{l}\text { No burnout } \\
(N=520)\end{array}$ & $\begin{array}{l}\text { OR }(95 \% \mathrm{CI}) \\
\text { parameter estimate }\end{array}$ & $p$ value \\
\hline \multicolumn{5}{|l|}{ Faculty professional behaviors } \\
\hline Being respectful of house staff and other physicians & & & & $<0.001$ \\
\hline Very often or always & $169(72.2 \%)$ & $480(92.3 \%)$ & Ref & \\
\hline Fairly often & $64(27.4 \%)$ & $39(7.5 \%)$ & $4.66(3.02,7.20)$ & \\
\hline Never, almost never & $1(0.4 \%)$ & $1(0.2 \%)$ & $2.84(0.18,45.66)$ & \\
\hline Being on time and managing a schedule well & & & & $<0.001$ \\
\hline Very often or always & $151(64.5 \%)$ & $431(83.0 \%)$ & Ref & \\
\hline Fairly often & $77(32.9 \%)$ & $88(17.0 \%)$ & $2.50(1.75,3.57)$ & \\
\hline Never, almost never & $6(2.6 \%)$ & $0(0.0 \%)$ & NA & \\
\hline Providing direction and constructive feedback & & & & $<0.001$ \\
\hline Very often or always & $97(41.5 \%)$ & $332(63.8 \%)$ & Ref & \\
\hline Fairly often & $122(52.1 \%)$ & $186(35.8 \%)$ & $2.24(1.63,3.10)$ & \\
\hline Never, almost never & $15(6.4 \%)$ & $2(0.4 \%)$ & $25.67(5.77,114.20)$ & \\
\hline Role-modeling wellness/self-care behaviors & & & & $<0.001$ \\
\hline Very often or always & $77(32.9 \%)$ & $358(69.0 \%)$ & Ref & \\
\hline Fairly often & $139(59.4 \%)$ & $151(29.1 \%)$ & $4.28(3.05,6.00)$ & \\
\hline Never, almost never & $18(7.7 \%)$ & $10(1.9 \%)$ & $8.37(3.72,18.84)$ & \\
\hline Finding resources in the moment needed to provide patient care & & & & $<0.001$ \\
\hline Very often or always & $144(61.8 \%)$ & $445(85.6 \%)$ & Ref & \\
\hline Fairly often & $85(36.5 \%)$ & $75(14.4 \%)$ & $3.50(2.44,5.03)$ & \\
\hline Never, almost never & $4(1.7 \%)$ & $0(0.0 \%)$ & NA & \\
\hline Encouraging free and open discussion of viewpoints, ideas, and beliefs & & & & $<0.001$ \\
\hline Very often or always & $113(48.3 \%)$ & $394(75.8 \%)$ & Ref & \\
\hline Fairly often & $96(41.0 \%)$ & $119(22.9 \%)$ & $2.81(2.00,3.95)$ & \\
\hline Never, almost never & $25(10.7 \%)$ & $7(1.3 \%)$ & $12.45(5.25,29.54)$ & \\
\hline
\end{tabular}

related to the risk of burnout. It is unclear from this study why this effect was observed to a greater extent in the intensive care setting than other settings. The physical presence of intensivists $24 / 7$ in the intensive care unit, potentially greater clinical role of fellows, and workload may have a role. It is, however, worth noting that the point estimates across clinical settings (Table 4) were all suggestive of a similar effect, and the $95 \%$ confidence intervals widely overlapped across clinical settings, suggesting the effect may not be limited to intensive care settings. These findings align with previous focus group and single-specialty studies reporting relationships between perceptions of independence, opportunities for learning, and resident well-being. ${ }^{14,27-30}$ Progressive autonomy is critical to residents' identity formation, sense of self-efficacy, and competency, as well as optimal patient care. ${ }^{31}$ Faculty must provide appropriate level of supervision ${ }^{16}$ and if too much or too little autonomy is provided tension between the faculty and the resident may increase. ${ }^{28} \mathrm{We}$ are unable to determine from our study if residents were dissatisfied with their autonomy due to being afforded too much independence or too little indepen- dence by supervising faculty. Too little autonomy may result in disengagement and negative feeling about one's tasks or be a marker of low-value work (e.g., administrative tasks) from which it is harder to obtain a sense of achievement or meaning - all of which could increase the risk of burnout. On the other hand, too much autonomy - particularly in the setting of high challenge - could amplify work stressors and sense of isolation, also increasing the risk of burnout. Multiple factors influence how much autonomy faculty provide residents, including patient acuity, complexity of the surgical procedure or medical care, residents' historical performance, faculty teaching strategies, and institutional policies. ${ }^{32-35}$ Efforts to improve residents' satisfaction with their autonomy in clinical decision-making should be considered as part of system-level strategies to improve resident well-being. ${ }^{4}$

Limitations of this study include residents training in one organization. Our cohort, however, was large, spanning multiple specialties, training sites (academic and community-based), and states. To our knowledge, the JHLES-faculty relationship subscale has not been previously used in a sample of residents,

Table 3 Relationship Between with Frequency of Each Faculty Professional Behavior Observed by Residents and Burnout

\begin{tabular}{lr}
\hline \hline Less frequent observation of faculty & Burnout, odds ratio (95\% CI)* \\
\hline Being respectful of house staff and other physicians & $\boldsymbol{p}$ value* \\
Being on time and managing a schedule well & $2.06(1.63,2.61)$ \\
Providing direction and constructive feedback & $2.06(1.64,2.57)$ \\
Modeling wellness/self-care behaviors & $1.79(1.50,2.13)$ \\
Finding resources in the moment needed to provide patient care & $2.14(1.79,2.55)$ \\
Encouraging free and open discussion of viewpoints, ideas, and beliefs & $2.07(1.69,2.54)$ \\
\hline
\end{tabular}

*Multivariable models controlled for age, sex, postgraduate year, and specialty. The odds ratios for burnout reflect the increased risk for burnout with a 1-unit decrease in reported frequency of the faculty professional behavior. For example, with all other factors being equal, a resident who has a 1-point lower score (less frequent) for exposure to faculty being respectful of house staff and other physicians is 2.06 times more likely to experience burnout 
Table 4 Association of Satisfaction with Autonomy in Various Clinical Settings and Burnout

\begin{tabular}{|c|c|c|c|c|c|c|}
\hline & \multicolumn{2}{|c|}{ Burnout status } & \multicolumn{2}{|l|}{ Bivariate analysis } & \multicolumn{2}{|c|}{ Multivariable analysis } \\
\hline & $\begin{array}{l}\text { Burnout, } \\
(N=\mathbf{2 3 6})\end{array}$ & $\begin{array}{l}\text { No } \\
\text { burnout } \\
(N=520)\end{array}$ & $\begin{array}{l}\text { OR } \\
(95 \% \text { CI })\end{array}$ & $p$ value & $\begin{array}{l}\text { OR } \\
(95 \% \text { CI })\end{array}$ & $p$ value* \\
\hline Patients in an intensive care unit & $151(88.8 \%)$ & $\begin{array}{l}358 \\
(94.0 \%)\end{array}$ & $0.51(0.27,0.96)$ & 0.03 & $\begin{array}{l}0.46(0.30 \\
0.70)\end{array}$ & $<0.001$ \\
\hline Patients undergoing a procedure or surgery & $180(90.5 \%)$ & $\begin{array}{l}417 \\
(95.9 \%)\end{array}$ & $0.41(0.21,0.80)$ & 0.01 & $\begin{array}{l}0.73(0.46 \\
1.15)\end{array}$ & 0.17 \\
\hline $\begin{array}{l}\text { Patients admitted to a non-intensive care unit hospital } \\
\text { bed }\end{array}$ & $195(95.6 \%)$ & $\begin{array}{l}413 \\
(98.3 \%)\end{array}$ & $0.37(0.13,1.00)$ & 0.04 & $\begin{array}{l}0.60(0.34 \\
1.07)\end{array}$ & 0.08 \\
\hline Patients seen in the outpatient setting (non-procedural) & $207(97.6 \%)$ & $\begin{array}{l}428 \\
(98.2 \%)\end{array}$ & $0.77(0.25,2.39)$ & 0.65 & $\begin{array}{l}0.69(0.40 \\
1.20)\end{array}$ & 0.19 \\
\hline
\end{tabular}

*Adjusted for gender, age, postgraduate year, and specialty

and we explored a limited number of faculty professional behaviors. Other factors associated with resident burnout were not accounted for in this analysis, including other relevant aspects of job demands and job resources. Additionally, as this study was cross-sectional, we cannot establish cause-effect relationships and we were unable to determine from our data if certain faculty receive low ratings by all residents, or if residents with burnout rated all their faculty low.

In conclusion, residents' perceptions of faculty-resident relationships and faculty professional behaviors and their satisfaction with autonomy in clinical decision-making were associated with resident burnout. Additional longitudinal studies are needed to determine the direction of these relationships, and if faculty development can mitigate the risk of resident burnout.

Supplementary Information The online version contains supplementary material available at https://doi.org/10.1007/s11606-02006452-3.

Corresponding Author: Liselotte N. Dyrbye, MD, MHPE; Mayo Clinic, Rochester, MN, USA (e-mail: dyrbye.liselotte@mayo.edu).

Funding Funding for this study was provided by the Mayo Clinic School of Graduate Medical Education Innovation Award and the Mayo Clinic Program on Physician Well-Being. This material is based upon work partially supported by a National Science Foundation (NSF) award under grant award number 2041339. Any opinions, findings, and conclusions or recommendations expressed in this material are those of the author(s) and do not necessarily reflect the views of the NSF.

\section{Compliance with Ethical Standards:}

Conflict of Interest: The authors declare that they do not have a conflict of interest.

Disclaimer: Funding sources had no role in the study design; in the collection, analysis, and interpretation of data; in the writing of the report; and in the decision to submit the article for publication.

\section{REFERENCES}

1. Dyrbye LN, Shanafelt TD. A narrative review on burnout experienced by medical students and residents. Med Educ 2016;50:132-49.
2. Dyrbye LN, Burke SE, Hardeman RR, et al. Association of clinical specialty with symptoms of burnout and career choice regret among us resident physicians. JAMA 2018;320:1114-30.

3. Attenello FJ, Buchanan IA, Wen T, et al. Factors associated with burnout among US neurosurgery residents: a nationwide survey. $J$ Neurosurg 2018:1-15.

4. National Academies of Sciences Engineering and Medicine: Taking action against clinician burnout a systems approach to professional well-being. Washington, DC: The National Academies Press; 2019.

5. West CP, Shanafelt TD, Kolars JC. Quality of life, burnout, educational debt, and medical knowledge among internal medicine residents. JAMA 2011;306:952-60.

6. Lu DW, Dresden SM, Mark Courtney D, Salzman DH. An investigation of the relationship between emergency medicine trainee burnout and clinical performance in a high-fidelity simulation environment. AEM Educ Train 2017;1:55-9.

7. West CP, Tan AD, Habermann TM, Sloan JA, Shanafelt TD. Association of resident fatigue and distress with perceived medical errors. JAMA 2009;302:1294-300.

8. West CP, Tan AD, Shanafelt TD. Association of resident fatigue and distress with occupational blood and body fluid exposures and motor vehicle incidents. Mayo Clin Proc 2012;87:1138-44.

9. Desai SV, Asch DA, Bellini LM, et al. Education outcomes in a dutyhour flexibility trial in internal medicine. N Engl J Med 2018;378:1494508.

10. Dyrbye LN, Lipscomb W, Thibault G. Redesigning the learning environment to promote learner well-being and professional development. Acad Med 2019;95:674-8.

11. Demerouti E, Bakker AB, Nachreiner F, Schaufeli WB. The job demands-resources model of burnout. J Appl Psychol 2001;86:499-512.

12. Oladeji LO, Ponce BA, Worley JR, Keeney JA. Mentorship in orthopedics: a national survey of orthopedic surgery residents. J Surg Educ 2018.

13. Hu Y-Y, Ellis RJ, Hewitt DB, et al. Discrimination, abuse, harassment, and burnout in surgical residency training. $N$ Engl $\mathrm{J}$ Med 2019;381:1741-52.

14. Verweij H, van der Heijden FMMA, van Hooff MLM, et al. The contribution of work characteristics, home characteristics and gender to burnout in medical residents. Adv Health Sci Educ Theory Pract 2017;22:803-18.

15. Mougalian SS, Lessen DS, Levine RL, et al. Palliative care training and associations with burnout in oncology fellows. J Support Oncol 2013;11:95-102.

16. ACGME. Common Program Requirements. Accessed 4/12/20 at https:// wwwacgmeorg/What-We-Do/Accreditation/Common-Program-Requirements 2019.

17. Dyrbye LN, Leep Hunderfund AN, Winters RC, et al. Residents' perceptions of their residency program leadership team behaviors and its relationship to their burnout and satisfaction. Acad Med In Press.

18. Shochet RB, Colbert-Getz JM, Wright SM. The Johns Hopkins Learning Environment Scale: measuring medical students' perceptions of the processes supporting professional formation. Acad Med 2015;90:810-8.

19. Tackett S, Wright S, Lubin $\mathbf{R}, \mathbf{L i} \mathbf{J}$, Pan $\mathbf{H}$. International study of medical school learning environments and their relationship with student well-being and empathy. Med Educ 2017;51:280-9. 
20. Association of American Medical Colleges. Year 2 Questionnaire. Washington, DC: Association of American Medical Colleges; 2019. Accessed at https://www.aamc.org/download/496618/data/y2q2018report.pdf on August 19, 2019. 2018.

21. Association of American Medical Colleges. Graduation Questionnaire. Washington, DC: Association of American Medical Colleges. Accessed at https://www.aamc.org/download/498790/data/2019gqallschoolssummaryreport.pdf on August 19, 2019. 2019.

22. West CP, Dyrbye LN, Satele D, Sloan J, Shanafelt TD. Concurrent validity of single-item measures of emotional exhaustion and depersonalization in burnout assessment. J Gen Intern Med 2012;27:1445-52.

23. West CP, Dyrbye LN, Sloan JA, Shanafelt TD. Single item measures of emotional exhaustion and depersonalization are useful for assessing burnout in medical professionals. J Gen Intern Med 2009;24:1318-21.

24. Norman GR, Sloan JA, Wyrwich KW. The truly remarkable universality of half a standard deviation: confirmation through another look. Expert Rev Pharmacoecon Outcomes Res 2004;4:515 - 9.

25. Pereira-Lima K, Gupta RR, Guille C, Sen S. Residency program factors associated with depressive symptoms in internal medicine interns: a prospective cohort study. Acad Med 2019;94:869-75.

26. Prins JT, Gazendam-Donofrio SM, Dillingh GS, van de Wiel HB, van der Heijden FM, Hoekstra-Weebers JE. The relationship between reciprocity and burnout in Dutch medical residents. Med Educ 2008;42:721-8.

27. Lases SS, Slootweg IA, Pierik E, Heineman E, Lombarts M. Efforts, rewards and professional autonomy determine residents' experienced well-being. Adv Health Sci Educ Theory Pract 2018;23:977-93.

28. Olmos-Vega FM, Dolmans D, Vargas-Castro N, Stalmeijer RE. Dealing with the tension: how residents seek autonomy and participation in the workplace. Med Educ 2017;51:699-707.
29. Golub J, Weiss P, Ramesh A, Ossoff R, Johns M. Burnout in residents of otolaryngology-head and neck surgery: a national inquiry into the health of residency training. Acad Med 2007;82:596-601.

30. Kimo Takayesu J, Ramoska EA, Clark TR, et al. Factors associated with burnout during emergency medicine residency. Acad Emerg Med 2014;21:1031-5

31. Farnan JM, Petty LA, Georgitis E, et al. A systematic review: the effect of clinical supervision on patient and residency education outcomes. Acad Med 2012;87:428-42.

32. Santen SA, Wolff MS, Saxon K, Juneja N, Bassin B. Factors affecting entrustment and autonomy in emergency medicine: "How much rope do I give them?". West J Emerg Med 2019;20:58-63.

33. Williams RG, George BC, Meyerson SL, et al. What factors influence attending surgeon decisions about resident autonomy in the operating room? Surgery 2017;162:1314-9.

34. Sandhu G, Magas CP, Robinson AB, Scally CP, Minter RM. Progressive entrustment to achieve resident autonomy in the operating room: a national qualitative study with general surgery faculty and residents. Ann Surg 2017;265:1134-40.

35. Sterkenburg A, Barach P, Kalkman C, Gielen M, ten Cate O. When do supervising physicians decide to entrust residents with unsupervised tasks? Acad Med 2010;85:1408-17.

Publisher's Note: Springer Nature remains neutral with regard to jurisdictional claims in published maps and institutional affiliations. 